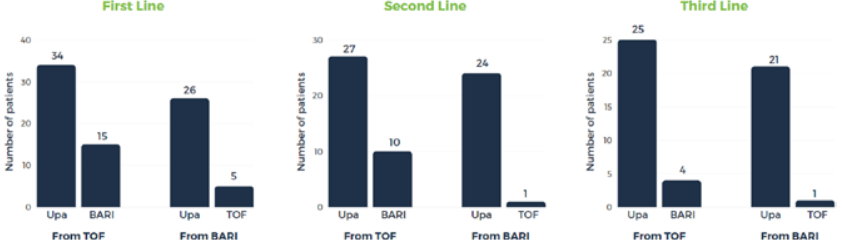

Figure 1. Patterns of JAKi cycling for the management of rheumatoid arthritis in first, second and third line switching.

Acknowledgements: The authors acknowledge the members of OPAL Rheumatology Ltd and their patients for providing clinical data for this study, and Software4Specialists Pty Ltd for providing the Audit4 platform

Disclosure of Interests: Sabina Ciciriello: None declared, Tegan Smith: None declared, Catherine OSullivan: None declared, Kathleen Tymms: None declared, Peter Youssef: None declared, David Mathers: None declared, Claire Deakin: None declared, Hedley Griffiths Consultant of: AbbVie, Gilead, Novartis and Lilly., Geoff Littlejohn Speakers bureau: Over the last 5 years Geoffrey Littlejohn has received educational grants and consulting fees from AbbVie, Bristol Myers Squibb, Eli Lilly, Gilead, Novartis, Pfizer, Janssen, Sandoz, Sanofi and Seqirus. DOI: 10.1136/annrheumdis-2021-eular.2256

\section{POS0224 SELECTIVITY OF CLINICAL JAK INHIBITORS AND THE IMPACT ON NATURAL KILLER (NK) CELL FUNCTIONAL RESPONSES}

P. Gonzalez-Traves ${ }^{1}$, L. Simpson ${ }^{1}$, B. Murray ${ }^{2}$, A. Meng ${ }^{3}$, J. A. Di Paolo ${ }^{4}$, E. Grant ${ }^{1}$, G. Min-Oo ${ }^{1}{ }^{1}$ Gilead Sciences, Inflammation Biology, Foster City, United States of America; ${ }^{2}$ Gilead Sciences, Drug Metabolism, Foster City, United States of America; ${ }^{3}$ Gilead Sciences, Clinical Pharmacology, Foster City, United States of America; ${ }^{4}$ Gilead Sciences, External Innovation, Foster City, United States of America

Background: Janus kinase (JAK) inhibitors (JAKinibs) show similar efficacy in rheumatoid arthritis (RA). However, in vitro studies have shown differences in JAK selectivity profiles for baricitinib (BARI), tofacitinib (TOFA), upadacitinib (UPA) and filgotinib (FIL). ${ }^{1,2}$ These lead to distinct pharmacologic profiles in cellular signaling assays that may impact clinical efficacy or safety ${ }^{1}$. NK cells are innate lymphocytes important in anti-pathogen responses and immune surveillance, which function via production of cytokines and cell killing ${ }^{3}$. NK cell proliferation and IFN $\gamma$ production are JAK-dependent pathways and may be modulated by JAKinibs. Clinical findings show transient decreases in NK cell numbers in patients treated with JAKinibs, but the link to safety is unclear ${ }^{4}$

Objectives: To extend upon findings in proximal cell signaling assays, we compared the selectivity and potency of clinical JAKinibs on NK cell function by assessing proliferation mediated by IL-15 (JAK1/3) and IFN- $\gamma$ production driven by IL-12 (JAK2/TYK2)+IL-18.

Methods: NK cells were isolated from healthy donor PBMC, incubated in vitro with 8 concentrations of each evaluated JAKinib (TOFA, BARI, FIL, FIL metabolite, UPA) and stimulated with IL-15 for proliferation or IL-12/18 for IFN $\gamma$ production. Proliferation was assessed by Cell Trace dye dilution after 6 days and IFN $\gamma$ production by intracellular flow cytometry $4 \mathrm{hrs}$ post-stimulation. Half maximal inhibitory concentration $\left(\mathrm{IC}_{50}\right)$ values were calculated for CD56 ${ }^{\text {bright }}, \mathrm{CD}^{\mathrm{dim}}$, and total NK cells. Steady-state pharmacologic profile over a clinical dosing interval was modeled using concentration-time profiles from JAKinib population pharmacokinetic data in RA subjects under the therapeutic dose ${ }^{5-7}$. For each JAKinib, the time above $I_{50}$ and average daily inhibition of IFN $\gamma$ or proliferation were calculated for each $\mathrm{NK}$ cell population in each donor.

Results: Cellular assays in purified NK cells showed dose-dependent inhibition of IL-15-induced proliferation by all JAKinibs with TOFA showing the highest average inhibition and time above $\mathrm{IC}_{50}$ (35-60\% inhibition for 8-15 hrs; TOFA $>U$ $\mathrm{PA}>\mathrm{BARI} \approx \mathrm{FIL})$. The differences between JAKinibs are in line with differences in pSTAT inhibition downstream of IL-15 $5^{1}$. Interestingly, IL-12/18-induced production of IFN $\gamma$, which is mediated via JAK2/TYK2 (IL-12) and non-JAK dependent pathways (IL-18), showed weaker inhibition for all compounds. Moreover, all JAKinibs showed $<25 \%$ average inhibition of IFN $\gamma$ production over $24 \mathrm{hrs}$ and did not show any time above $\mathrm{IC}_{50}$ for IFN $\gamma$ production or PSTAT4 inhibition at clinical doses. $\mathrm{CD}^{\mathrm{dim}}$ and CD56 $6^{\text {bright }}$ sub-populations of NK cells are proposed to have distinct functions and unique expression of surface receptors. Analysis of the $\mathrm{IC}_{50}$ for pSTAT4 and IFN $\gamma$ production showed $~ 2-10$-fold weaker inhibition by JAKinibs in CD56 $6^{\text {bright }}$ NK cells, suggesting less dependence on JAK-dependent signals in CD56 ${ }^{\text {bright }}$ NK cells than CD56 ${ }^{\text {dim }}$ NK cells.

Conclusion: NK cell proliferation depends on JAK1 and JAK3-mediated signaling and is differentially inhibited at clinical doses of distinct JAKinibs. In contrast, functional responses downstream of JAK2/TYK2-dependent IL-12/18 were not substantially inhibited by any of the JAKinibs studied. Inhibition of functional and proliferative responses in purified NK cells aligned well with proximal pSTAT inhibition. JAKinib modulation of NK cell proliferation, but not response to IL-12, reflects unique pharmacologic profiles of the drugs studied and could be one component underlying clinical safety observations, including increased risk of viral infections or malignancy ${ }^{4}$.

REFERENCES:

[1] Traves PG et al. Ann Rheum Dis 2021 (in press)

[2] Mclnnes IB, et al. Arthritis Res Ther 2019;21:183.

[3] Cooper MA, Fehniger TA, Caligiuri MA. Trends Immunol 2001 Nov;22(11):633-40.

[4] Winthrop KL. Nat Rev Rheumatol 2017; 13(4):234-243

[5] Zhang X, et al. CPT Pharmacometrics Syst Pharmacol 2017;6(12):804-13.

[6] CDER. Application Number: 203214Orig1s000. NDA 203214: Tofacitinib.

[7] Klunder B et al. Clin Pharmacokinet 2019;58(8):1045-58.

Disclosure of Interests: Paqui Gonzalez-Traves Shareholder of: Gilead Sciences, Employee of: Gilead Sciences, Laura Simpson Shareholder of: Gilead Sciences, Employee of: Gilead Sciences, Bernard Murray Shareholder of: Gilead Sciences, Employee of: Gilead Sciences, Amy Meng Shareholder of: Gilead Sciences, Employee of: Gilead Sciences, Julie A. Di Paolo Shareholder of: Gilead Sciences, Employee of: Gilead Sciences, Ethan Grant Shareholder of: Gilead Sciences, Employee of: Gilead Sciences, Gundula Min-Oo Shareholder of: Gilead Sciences, Employee of: Gilead Sciences DOI: 10.1136/annrheumdis-2021-eular.2741

POS0225

RISK OF MAJOR CARDIOVASCULAR EVENT ACROSS JAK INHIBITOR TREATED PATIENTS: ANALYSIS OF A NATIONAL CLAIM DATABASE

A. Gouverneur $^{1,2}$, J. Avouac ${ }^{3}$, C. Prati ${ }^{4}$, J. L. Cracowski ${ }^{5}$, T. Schaeverbeke ${ }^{6}$, A. Pariente ${ }^{1,2}$, M. E. Truchetet ${ }^{6} .{ }^{1}$ University of Bordeaux, Inserm, Bordeaux Population Health Research Center, Pharmacoepidemiology Team, UMR 1219, Bordeaux, France; ${ }^{2} \mathrm{CHU}$ of Bordeaux, Pôle de Santé Publique, Service de Pharmacologie, Bordeaux, France; ${ }^{3}$ Université de Paris, Service de Rhumatologie, Hôpital Cochin, AP-HP.CUP, Paris, France; ${ }^{4}$ University Hospital CHU Minjoz, Rheumatology Unit, Besancon, France; ${ }^{5}$ Université Grenoble Alpes, INSERM, HP2, Grenoble, France; ${ }^{6} \mathrm{CHU}$ de Bordeaux, Hôpital Pellegrin, Department of Rheumatology, National Reference Center for Systemic Autoimmune Rare Diseases, Bordeaux, France

Background: Inhibiting a specific JAK may impede more than one pathway, explaining both the efficacy and adverse effects observed with JAK inhibitors (JAKi). Among those, there have been recent concerns about potential thromboembolic risks with these drugs. As patients enrolled are not representative of all patients who may receive $\mathrm{JAKi}$, data from trials are unlikely to provide definitive answers. Real impact of JAKi in real life on major cardiovascular events is not known.

Objectives: To evaluate the risk of venous and arterial thromboembolic events with the use of JAKi in a real-world setting.

Methods: A self-controlled case series analysis (method in which individuals act as their own control) was performed using data from the French national healthcare insurance system SNDS ("Système National des Données de Santé"), which included all anonymized individual level data about sociodemographic data, outpatient healthcare dispensed, hospital discharge summaries, and registration status for a list of 30 long term diseases. All patients treated by JAKi (baricitinib or tofacitinib) for rheumatoid arthritis, psoriasis arthritis and/or inflammatory bowel disease, and with at least one thromboembolic event (venous (VTE): deep vein thrombosis (DVT), pulmonary embolism (PE), arterial (ATE): acute coronary syndrome (ACS), myocardial infarction (MI), transient ischemic attack (TIA) and stroke) between 2017/11/01 and 2019/06/30 were included in the study. Associations were evaluated by incidence rate ratios (IRR), which compare the rate of events during exposed periods with rate of event during all other observed time periods. Exposed periods were defined as i) exposure to JAKi, ii) the month following exposure (post-exposure 1-30 days), and iii) long-term post-exposure (31 to 60 days). A pre-exposure period of 7 days was individualized to identify event-dependent probabilities of exposure and potential reverse causality bias, and all other periods were considered as non-exposed periods.

Results: Among the 5,870 patients treated with JAKi between 2017/11/01 and 2019/06/30, 94 presented an incident thromboembolic event and were included. Almost two thirds were female $(n=61,64.9 \%)$, and median age was 65.4 [IQR: $55.5 ; 75.8$ ] years. Most of patients have a rheumatoid arthritis ( $n=91,96.8 \%)$, $62(66.0 \%)$ were treated by baricitinib, and $32(34.0 \%)$ by tofacitinib. Almost half $(n=42,44.7 \%)$ presented a venous thromboembolism, mainly DVT $(n=31$, $33.0 \%)$, and $52(55.3 \%)$ presented an arterial thromboembolism, mainly $\mathrm{Ml}$ $(n=16,17.0 \%)$ and stroke $(n=14,14.9 \%)$. Eleven patients $(11.7 \%)$ died during the study period. The median time of occurrence of VTE was 4.3 [IQR: $2.5 ; 8.9$ ] months, and 6.1 [IQR: 3.3; 9.2] months for ATE. 